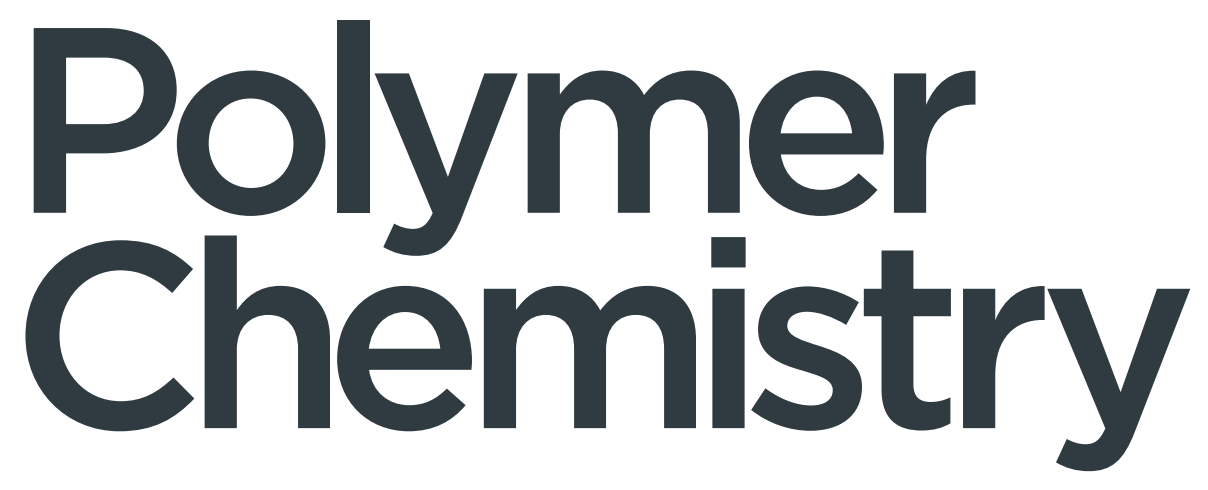

Volume 11

Number 44

28 November 2020

Pages 6981-7116

rsc.li/polymers
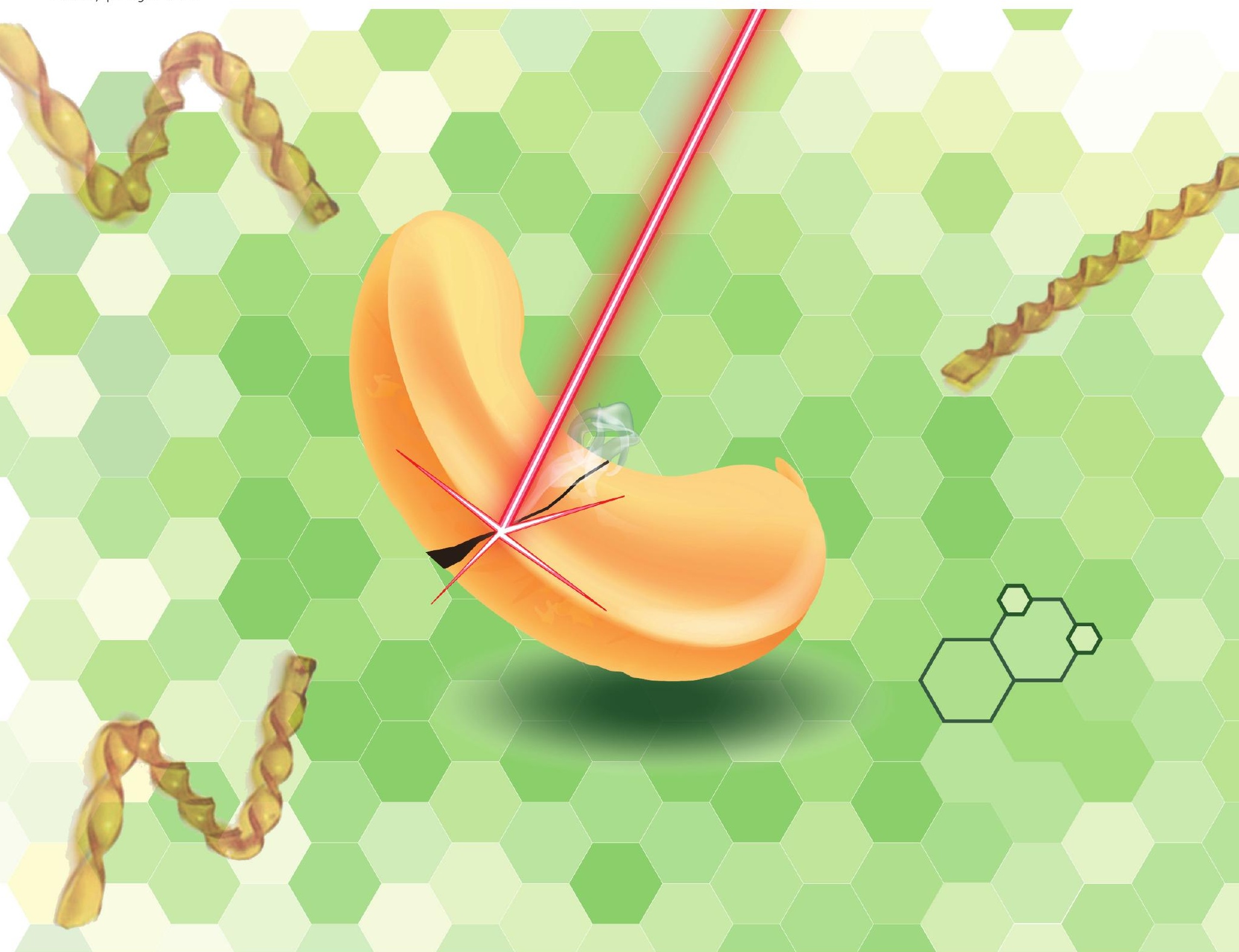

ISSN 1759-9962

ROYAL SOCIETY OF CHEMISTRY

\section{PAPER}

Pierre Verge et al.

A cardanol-based polybenzoxazine vitrimer: recycling, reshaping and reversible adhesion 


\section{D) Check for updates}

Cite this: Polym. Chem., 2020, 11 7026

Received 31st August 2020, Accepted 23rd September 2020

DOI: $10.1039 / \mathrm{d} 0$ py01239d

rsc.li/polymers

\title{
A cardanol-based polybenzoxazine vitrimer: recycling, reshaping and reversible adhesion $\uparrow$
}

\begin{abstract}
Acerina Trejo-Machin, ${ }^{a, b}$ Laura Puchot ${ }^{a}$ and Pierre Verge (D) *a
This paper reports the development of the first vitrimer based on polybenzoxazines containing disulfide bonds and cardanol. The synthesis of the monomer was carried out following a sustainable process, without any solvent and purification. The novel polybenzoxazine can be recycled, reshaped and (re)processed, thanks to a fast relaxation process (18 seconds at $120{ }^{\circ} \mathrm{C}$ ) and low activation energy $(64.5 \mathrm{~kJ}$ $\mathrm{mol}^{-1}$ ). Furthermore, the benzoxazine vitrimer shows significant and healable adhesive properties over short times and at low temperatures. These features support it also being considered in additive manufacturing applications, with the possibility of applying 3D printing technology, extending its application to many fields of materials.
\end{abstract}

\section{Introduction}

Plastic pollution has become one of the major global environmental issues. The development of more sustainable and smart materials has become essential to overcome this rapidly growing problem. ${ }^{1,2}$ In particular, composites made with traditional thermosets are disposed of in landfill sites as they cannot be re-processed or recycled. This drawback is inherent to their 3D chemical structure. ${ }^{3,4}$

In addition to environmental considerations and societal pressure, safety legislations are also increasingly challenging for traditional phenolic or epoxy resins. ${ }^{5}$ The release of formaldehyde, phenol, resorcinol, or diamine compounds during the curing and processing steps of thermosets is of serious concern. Due to their chemical structure, polybenzoxazines (poly(Bz)) are not subject to the release of these chemicals, and this and their self-catalyzed polymerization are two clear assets in the composite arena. ${ }^{6,7}$ They exhibit outstanding and competitive properties such as high thermal stability, ${ }^{8}$ nearzero shrinkage upon polymerization, ${ }^{9}$ excellent thermal, mechanical and dielectric properties, ${ }^{10-12}$ low water absorption, and low flammability, ${ }^{13}$ making them a suitable alternative to phenolic and epoxy resins. ${ }^{6}$ In addition, the versatility of their chemical design is a great platform for the use of

${ }^{a}$ Luxembourg Institute of Science and Technology, Materials and Research Technology Department, 5 Avenue des Hauts-Fourneaux, L-4362 Esch-sur-Alzette, Luxembourg. E-mail: pierre.verge@list.lu

${ }^{b}$ University of Luxembourg, 2 avenue de l'université, L-4365 Esch-sur-Alzette,

Luxembourg

$\dagger$ Electronic supplementary information (ESI) available. See DOI: 10.1039/ d0py01239d renewable feedstock. ${ }^{14,15}$ Cardanol, ${ }^{16-18}$ vanillin, ${ }^{19,20}$ and many other bio-phenols ${ }^{21,22}$ have been used with success to create bio-based polybenzoxazines. However, like other thermosets, polybenzoxazines lack both recyclability and (re) processability.

This issue could be tackled by introducing dynamic covalent bonds or non-covalent interactions into their macromolecular structure. This new concept is known as covalent adaptable networks (CANs). ${ }^{23-25}$ CANs are either dissociative or associative depending on their mechanism of rearrangement. Dissociative CANs proceed first by bond cleavage followed by bond formation (Diels-Alder reaction, for instance). Conversely, in associative CANs (or vitrimers), linkages create permanent networks where bonds are only broken as new ones are formed, keeping the crosslinking density of the network constant. In both cases, the dynamic bonds enable a crosslinked network structure while the dynamicity of the bonds enables the network to reorganize. Irrespective of whether crosslink exchanges are associative or dissociative, CANs have emerged at the macroscale level as a hot topic in polymer and materials science, unlocking the development of more environmentally friendly thermosets. ${ }^{26-29}$ In particular, the disulfide exchange reaction is of growing interest as it has been proven to show dynamicity at room temperature without the need for a catalyst. ${ }^{30-33}$

Combining dynamic exchanges and benzoxazine chemistry has been barely investigated. Yagci, Kiskan et al. reported different strategies to develop healable poly $(\mathrm{Bz})$ based on Friedel-Crafts reactions, ${ }^{34}$ photo-induced coumarine dimerization, ${ }^{35}$ supramolecular hydrogen bonding, ${ }^{36}$ ketene chemistry, ${ }^{37}$ metal-ligand interactions, ${ }^{38}$ or dynamic sulfide linkages. ${ }^{39}$ However, to the best of our knowledge, none of the 
self-healable or reprocessable poly $(\mathrm{Bz})$ reported so far demonstrates thermally activated stress relaxation as a result of fast topological rearrangement. Therefore, the evidence of benzoxazine-based vitrimers has never been reported.

This publication describes the first vitrimer polybenzoxazine thermoset that can be recycled, reshaped, (re)processed, and used as a reversible and self-healable adhesive. To bring dynamicity to the material, a disulfide diamine was used to synthesize the benzoxazine monomer. Cardanol was selected as the bio-phenolic compound to synthesize the benzoxazine with the aim to obtain an easily processable system thanks to the presence of the long alkyl chain. ${ }^{17,40}$ In addition, it is a non-edible waste arising from the cashew industry. The following paragraphs describe the preparation and unique properties of this new material that relies on cutting-edge vitrimer chemistry, fitting many of the green chemistry and engineering principles.

\section{Experimental part}

\section{Materials}

Cardanol (Ultralite 2023, 96\%) was supplied by Cardolite. Paraformaldehyde (95\%), 3-pentadecylphenol (90\%), 4-aminophenyl disulfide (98\%), 4,4'-ethylenedianiline (95\%), chloroform-d $\left(\mathrm{CDCl}_{3}\right)$, and solvents used for the solubility test (dimethylformamide (DMF), acetone, ethanol and ethylacetate (EtAc)) were purchased from Sigma-Aldrich and used as received.

\section{Methods}

Nuclear magnetic resonance (NMR). NMR spectra were recorded using an AVANCE III HD Bruker spectrometer operating at a frequency of $600 \mathrm{MHz}$ and equipped with a $5 \mathrm{~mm} \mathrm{BBO}$ probe. The samples were dissolved in deuterated chloroform $\left(\mathrm{CDCl}_{3}\right)$ and the spectra were referenced relative to tetramethylsilane (TMS). Assignments were performed using a combination of COSY, HSQC, and HMBC spectra. Peak multiplicity was indicated as follows: singlet (s), doublet (d), or multiplet (m). The integrations are usually calculated by moderation based on the abundance of unsaturation described in the literature. ${ }^{17}$ The difference in relaxation times between the aromatic and aliphatic hydrogen complicates the accurate quantification of all protons. Therefore, the peaks related to the aliphatic chain of cardanol were integrated into the aliphatic hydrogen in the $\beta$ position of the cardanol aromatic ring, which should integrate for $2 \mathrm{H}$, whereas the peak from $\mathrm{H}-\mathrm{Ar}$ from the 4-aminophenyl disulfide compound that should integrate for $1 \mathrm{H}$ was used as the reference for all other peaks, including those related to the benzoxazine structure.

Fourier transform infrared spectroscopy (FTIR). FTIR was conducted on a Bruker TENSOR 27 (Ettlingen, Germany) system in the attenuated total reflection (ATR) mode using a diamond crystal. The background and sample spectra were recorded at $4 \mathrm{~cm}^{-1}$ spectral resolution across the $4000-400 \mathrm{~cm}^{-1}$ range.
Elemental analysis. The CHNS measurements were performed on a Vario MACRO cube CHNS/O from Elementar France SARL. Samples were inserted in an oxygen-enriched furnace at $1150{ }^{\circ} \mathrm{C}$ where a combustion process converted carbon to carbon dioxide, hydrogen to water, nitrogen to nitrogen gas/oxides of nitrogen and sulfur to sulfur dioxide. The combustion products were swept out of the combustion chamber by an inert carrier gas (helium, $600 \mathrm{ml}$ per minute) and passed over heated $\left(850{ }^{\circ} \mathrm{C}\right)$ high-purity copper. Separation of the measuring components took place as follows: $\mathrm{N}_{2}$ was not adsorbed in the adsorption columns and was the first measuring component to enter directly into the thermal conductivity detector. The other components were adsorbed in their respective adsorption columns. Each of these columns was then separately heated to the corresponding desorption temperature $\left(T_{\text {desorpt. }}\right)$ in order to release the components in the following order: $\mathrm{CO}_{2}\left(T_{\text {desorpt. }} 240{ }^{\circ} \mathrm{C}\right)$, $\mathrm{H}_{2} \mathrm{O}\left(T_{\text {desorpt. }} 150^{\circ} \mathrm{C}\right)$ and $\mathrm{SO}_{2}\left(T_{\text {desorpt. }} 100^{\circ} \mathrm{C}\right.$ or $\left.230^{\circ} \mathrm{C}\right)$. After desorption, each component was transported by the carrier gas flow into the measuring cell of a thermal conductivity detector (TCD).

Raman spectroscopy. The Raman spectrum was recorded in a back-scattering geometry with a Renishaw inVia Reflex Raman microscope using the $442 \mathrm{~nm}$ line of a $\mathrm{He}-\mathrm{Cd}$ laser, and 10 accumulations of $10 \mathrm{~s}$ were used at a power of $24.3 \mathrm{~mW}$. A $\times 50$ long working distance objective was used to focus the laser beam on the sample surface.

Differential scanning calorimetry (DSC). DSC thermograms were recorded using a Netzsch DSC 204 F1 Phoenix apparatus operating under an inert atmosphere (nitrogen) with a linear heating ramp from 20 to $250^{\circ} \mathrm{C}$ at $10^{\circ} \mathrm{C} \mathrm{min}^{-1}$ rate.

Thermo-gravimetric analysis (TGA). TGAs were performed using a Netzsch TG 409 PC Luxx device operating under nitrogen with a heating ramp of $10^{\circ} \mathrm{C} \min ^{-1}$ up to $800{ }^{\circ} \mathrm{C}$.

Rheo-kinetic test. Rheo-kinetic measurements were performed using an Anton Paar Physica MCR 302 rheometer equipped with a CTD 450 temperature control device with a disposable aluminum plate-plate (diameter: $25 \mathrm{~mm}$, measure gap: $0.35 \mathrm{~mm}$ ) geometry. The polymerization measurements were recorded in the oscillation mode with a linear strain amplitude from 1 to $0.1 \%(\gamma)$ and a frequency $(f)$ of $1 \mathrm{~Hz}$. The test was performed following a heating ramp of $20{ }^{\circ} \mathrm{C} \mathrm{min}^{-1}$ from $50{ }^{\circ} \mathrm{C}$ to $170{ }^{\circ} \mathrm{C}$ followed by an isothermal measurement at $170{ }^{\circ} \mathrm{C}$.

Dynamic mechanical analyses (DMAs). DMAs were performed on a Netzsch DMA 242C apparatus on $5 \times 7.85 \times$ $2 \mathrm{~cm}^{3}$ rectangular specimens cut from molded bars. They were tested in the simple cantilever mode of flexural loading (2-point bending) with a maximum displacement of $40 \mu \mathrm{m}$ from $-50{ }^{\circ} \mathrm{C}$ to $120{ }^{\circ} \mathrm{C}$ (rate $2^{\circ} \mathrm{C} \mathrm{min}^{-1}$ ) and a frequency of $1 \mathrm{~Hz}$.

Swelling tests. Swelling tests were performed in dimethylformamide (DMF), ethanol, acetone, ethyl acetate and neutral $\mathrm{H}_{2} \mathrm{O}$. Samples were about $5 \times 5 \times 1 \mathrm{~mm}$ and $25 \mathrm{mg}( \pm 2 \mathrm{mg})$ for each experiment and were immersed in $2 \mathrm{~mL}$ of the corresponding solvent for $48 \mathrm{~h}$ at room temperature. The sample 
with neutral $\mathrm{H}_{2} \mathrm{O}$ was then heated up to $50{ }^{\circ} \mathrm{C}$ and kept for $48 \mathrm{~h}$ at this temperature.

$$
\begin{gathered}
\text { Swelling ratio }(\%)=\frac{m_{\mathrm{s}}-m_{\mathrm{i}}}{m_{\mathrm{i}}} \times 100 \\
\text { Soluble fraction }(\%)=\frac{m_{\mathrm{i}}-m_{\mathrm{d}}}{m_{\mathrm{i}}} \times 100
\end{gathered}
$$

where $m_{\mathrm{i}}, m_{\mathrm{s}}$, and $m_{\mathrm{d}}$ are, respectively, initial, swollen, and dry mass.

Frequency sweep tests and stress relaxation tests. Frequency sweep and stress relaxation measurements were performed using an Anton Paar Physica MCR 302 rheometer equipped with a CTD 450 temperature control device with a disposable aluminum plate-plate (diameter: $25 \mathrm{~mm}$, measure gap: $0.35 \mathrm{~mm}$ ) geometry. The samples were maintained at the measurement temperature for 10 minutes at a constant gap. An amplitude of deformation of $0.5 \%$ was applied with the frequency ranging from $0.01 \mathrm{rad} \mathrm{s}^{-1}$ to $500 \mathrm{rad} \mathrm{s}^{-1}$. Stress relaxation measurements were carried out in a second step. An amplitude deformation of $1 \%$ was applied and the relaxation modulus followed as a function of time.

Thermo-mechanical properties. Dynamic mechanical thermal analyses of neat poly(CAR-4apds) and recycled poly (CAR-4apds) were performed using an Anton Paar Physica MCR 302 rheometer equipped with a CTD 450 temperature control device with a disposable aluminum plate-plate (diameter: $25 \mathrm{~mm}$, measure gap: $0.35 \mathrm{~mm}$ ) geometry. They were tested with an amplitude of $1 \%$ maximum displacement from $20{ }^{\circ} \mathrm{C}$ to $125{ }^{\circ} \mathrm{C}$ (rate $2{ }^{\circ} \mathrm{C} \mathrm{min}^{-1}$ ) and a frequency of $1 \mathrm{~Hz}$.

Tensile test. Tensile pull-off tests were performed on an electromechanical testing machine INSTRON 5967 with a grip separation of $2 \mathrm{~mm} \mathrm{~min}^{-1}$. The adhesive film with dimensions of $5 \mathrm{~cm} \times 5 \mathrm{~cm} \times 0.5 \mathrm{~mm}$ was placed in between two aluminum cubes $(15 \mathrm{~cm} \times 5 \mathrm{~cm} \times 5 \mathrm{~cm})$. After that, a thermal treatment was carried out at $120{ }^{\circ} \mathrm{C}$ for $10 \mathrm{~min}$. Then, the system was cooled down. After the tensile test, the blocks were reassembled applying a pressure of 1 or 8 bars and the same thermal treatment $\left(120^{\circ} \mathrm{C}\right.$ for $\left.10 \mathrm{~min}\right)$.

\section{Synthesis of CAR-4apds}

Cardanol (11.9 g, 40 mmol, 1 eq.), 4-aminophenyl disulfide (4.97 g, $20 \mathrm{mmol}, 0.5$ eq.), and paraformaldehyde (2.4 g, $80 \mathrm{mmol}, 2$ eq.) were reacted together in a round-bottom flask under mechanical stirring at $85{ }^{\circ} \mathrm{C}$ for $7 \mathrm{~h}$ (Scheme 1a). No purification was required. The yield was $95 \%$.

${ }^{1} \mathrm{H} \mathrm{NMR}\left(\mathrm{CDCl}_{3}, 600 \mathrm{MHz}, 298 \mathrm{~K}\right), \delta(\mathrm{ppm})=$ (assignment, multiplicity, [attribution], experimental integration, theoretical integration); $\delta=0.87-0.97\left(-\mathrm{CH}_{3}, \mathrm{~m},\left[\mathrm{a}_{1}\right]\right.$ from cardanol alkyl chain, exp. $4.06 \mathrm{H}$, th. $3.54 \mathrm{H}), 1.18-1.46\left(-\mathrm{CH}_{2}, \mathrm{~s},\left[\mathrm{~b}_{1}, \mathrm{c}_{1}, \mathrm{~d}_{1}, \mathrm{e}_{1}\right.\right.$, $\left.\mathrm{f}_{1}, \mathrm{~g}_{1}, \mathrm{~h}_{1}, \mathrm{i}_{1}, \mathrm{j}, \mathrm{k}, \mathrm{l}, \mathrm{m}\right]$ from cardanol alkyl chain, exp. $26.36 \mathrm{H}$, th. $27.12 \mathrm{H}), 1.52-1.66\left(-\mathrm{CH}_{2} \beta\right.$ from $\mathrm{Ar}, \mathrm{s},[\mathrm{n}]$, aliphatic proton ref. $4.00 \mathrm{H}), 1.96-2.12\left(\mathrm{CH}_{2}{ }^{*}=\mathrm{CH}, \mathrm{m},\left[\mathrm{c}_{2}, \mathrm{f}_{2}, \mathrm{i}_{2}\right]\right.$, exp. $7.02 \mathrm{H}$, th. $6.20 \mathrm{H}), 2.46-2.61\left(\mathrm{CH}_{2}-\mathrm{Ar}, \mathrm{m},[\mathrm{o}]\right.$, exp. $3.97 \mathrm{H}$, th. $\left.4.00 \mathrm{H}\right)$, 2.70-2.90 $\left(\mathrm{CH}_{2}{ }^{*}(=\mathrm{CH})_{2}, \mathrm{~d},\left[\mathrm{c}_{3}, \mathrm{f}_{3}\right]\right.$, exp. $3.80 \mathrm{H}$, th. $\left.4.20 \mathrm{H}\right), 4.62$ $\left(\mathrm{Ar}-\mathrm{CH}_{2}-\mathrm{N}, \mathrm{s},[4]\right.$, exp. 3.76H, th. $\left.4.00 \mathrm{H}\right), 5.34\left(\mathrm{O}-\mathrm{CH}_{2}-\mathrm{N}, \mathrm{s},[5]\right.$, exp. $3.95 \mathrm{H}$, th. $4.00 \mathrm{H}), 4.96-5.88\left(\mathrm{CH}=, \mathrm{m}, \mathrm{m}, \mathrm{m},\left[\mathrm{a}_{2},\left(\mathrm{~d}_{2}, \mathrm{e}_{2}\right.\right.\right.$, a

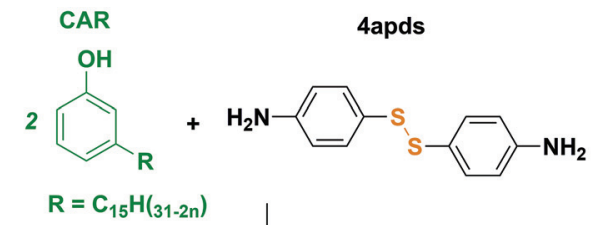

b CAR-4apds
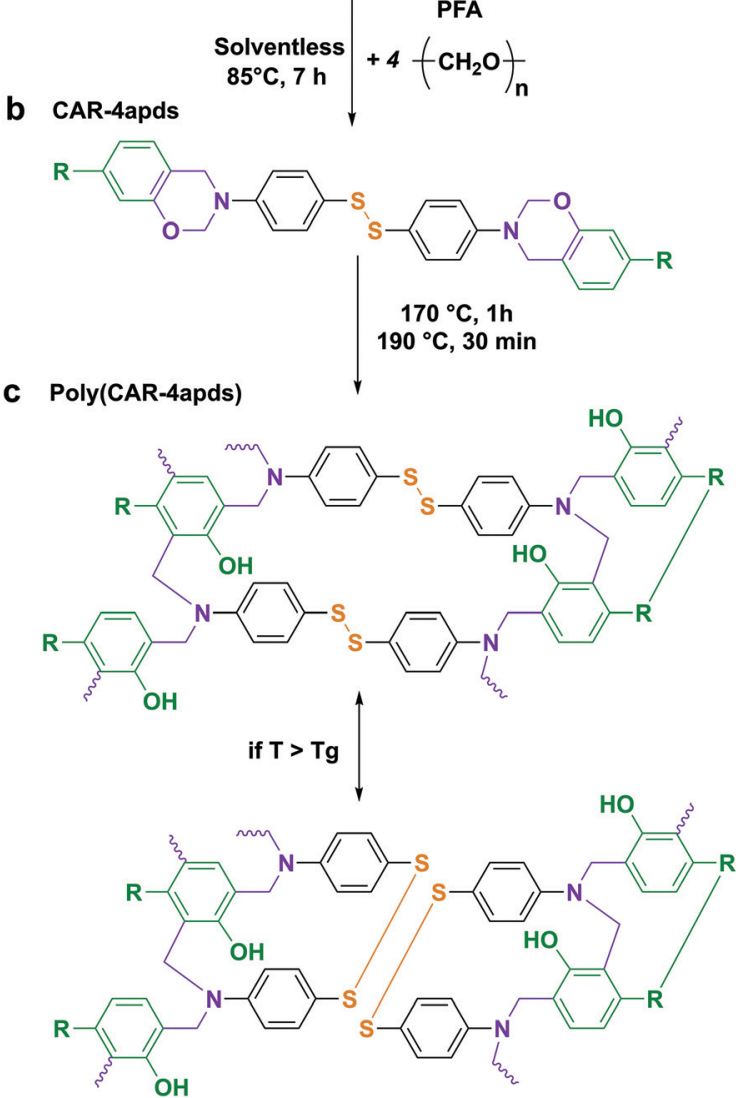

Scheme 1 Chemical structure of the disulfide-benzoxazine vitrimer. (a) Synthetic route of CAR-4apds ( $n$ can be $0,1,2$ or 3). (b) Schematic representation of the CAR-4apds monomer and polymerization conditions. (c) Simplified cross-linked network and mechanism of chemical bond re-arrangement upon heating showing the dynamic properties of poly (CAR-4apds).

$\left.\left.\mathrm{g}_{2}, \mathrm{~h}_{2}\right), \mathrm{b}_{2}\right]$, exp. 1.51, 5.80, $0.70 \mathrm{H}$, th. 1.64, 6.48, $\left.0.82 \mathrm{H}\right)$, 6.60-6.90 (H-Ar from cardanol, s, d, [1, 2, 3], exp. 2.22, 2.05, $2.02 \mathrm{H}$, th. 2.00, 2.00, 2.00H), 7.04 ( $\mathrm{H}$-Ar from 4-aminophenyl disulfide, d, $[6,7]$, benzoxazine structure reference th. $4.00 \mathrm{H}$ ), 7.39 (H-Ar from 4-aminophenyl disulfide, d, [8,9], exp. $4.00 \mathrm{H}$, th. $4.00 \mathrm{H})$.

FTIR $\left(\mathrm{cm}^{-1}\right): 2920$ and 2850 (C-H stretching), 1505 (vibration trisubstituted benzene ring), 1236 (C-O-C oxazine asymmetric stretching), 960 (out-of-plane bending vibration of the benzene ring).

Elemental analysis: element (exp., th.); $\mathrm{N}$ (3.02, 3.10); C (77.06, 76.99); H (9.18, 9.29); S (7.21, 7.08); O (3.53, 3.54).

Additional molecules synthesized for the sake of comparison and investigation of the mechanism of curing of CAR-4apds are reported in the ESI (Schemes S1, S2 and Fig. S1, S2 $\dagger$ ). 


\section{Results and discussion}

Synthesis, characterization, and polymerization of CAR-4apds

Thermoset polybenzoxazines are commonly obtained by crosslinking di-functional benzoxazine monomers. Di-functional benzoxazines (or dibenzoxazines) can be obtained from the reaction of a diamine with mono-phenolic compounds. Towards the objective of synthesizing a dibenzoxazine containing a disulfide bond, 4-aminophenyl disulfide, which is composed of two aniline rings bridged by a disulfide bond, appeared to be an excellent candidate. Additionally, cardanol, a bio-based phenolic compound, was reacted with the aim of designing a low cross-linking density polymer to promote its macroscopic flow during the reprocessing steps. ${ }^{17,40}$ The novel benzoxazine monomer (CAR-4apds) containing disulfide is shown in Scheme 1b and was easily synthesized by a solventless approach from cardanol (CAR), 4-aminophenyl disulfide (4apds) and paraformaldehyde in 7 hours at $85{ }^{\circ} \mathrm{C}$. The success of the reaction was assessed by NMR confirming the formation of the oxazine ring by the appearance of two new peaks at $\delta=5.34$ and $4.62 \mathrm{ppm}$ corresponding to the protons from $\mathrm{O}-\mathrm{CH}_{2}-\mathrm{N}$ and $\mathrm{Ar}-\mathrm{CH}_{2}-\mathrm{N}$ respectively (see Fig. 1). Assignment of all the peaks and integration values are described in the Experimental section. In addition, in the FTIR spectrum, bands at 960 and $1236 \mathrm{~cm}^{-1}$ corresponding to ring vibration and $\mathrm{C}-\mathrm{O}-\mathrm{C}$ stretching, respectively, were observed confirming the synthesis of the benzoxazine monomer (see Fig. S3 in the ESI $\dagger$ ). The presence of disulfide bonds was confirmed by Raman analysis (see Fig. S4 in the ESI†).

The thermal behavior of CAR-4apds was characterized by DSC and TGA (Fig. 2a). An endothermic peak corresponding to the melting $\left(T_{\mathrm{m}}\right)$ of the monomer is observed on the DSC ther- a
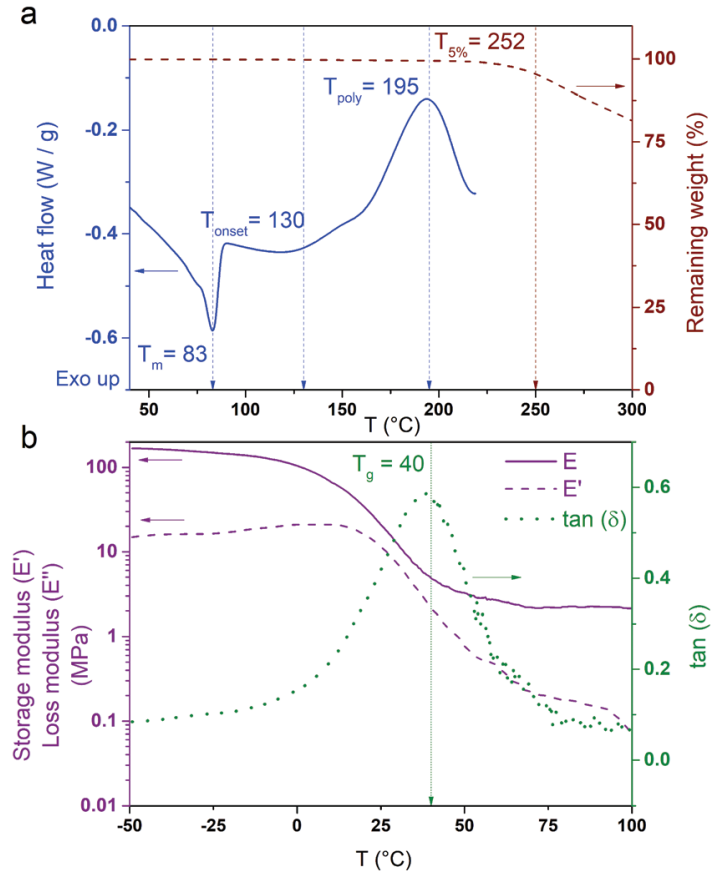

Fig. 2 (a) DSC thermogram $\left(\mathrm{N}_{2}, 10^{\circ} \mathrm{C} \mathrm{min}^{-1}\right)$ of CAR-4apds overlapped with TGA $\left(\mathrm{N}_{2}, 10^{\circ} \mathrm{C} \mathrm{min}^{-1}\right.$ ). (b) DMTA thermogram of poly(CAR-4apds). Storage modulus $\left(E^{\prime}\right)$ : solid line, loss modulus $\left(E^{\prime \prime}\right)$ : dashed line and tan $(\delta)$ : dotted line.

mogram at around $83{ }^{\circ} \mathrm{C}$. The onset of an exothermic peak ( $T_{\text {onset }}$ ) is observed at $130{ }^{\circ} \mathrm{C}$ with a maximum at $195{ }^{\circ} \mathrm{C}$, attributed to the thermally activated ring-opening polymerization $\left(T_{\text {poly }}\right)$ of the benzoxazine monomer. In addition, in accordance with TGA, CAR-4apds can be heated up to $252^{\circ} \mathrm{C}$ without early degradation. The viscoelastic behavior of CAR-4apds was

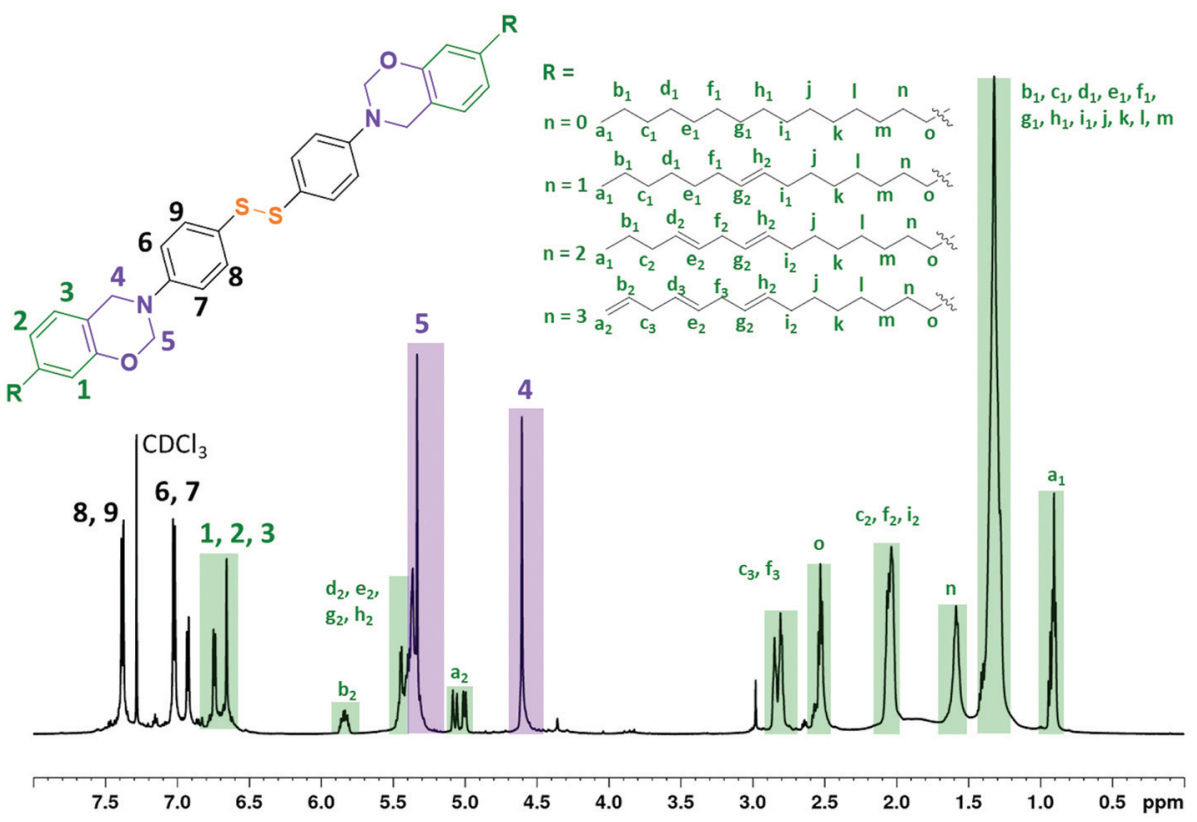

Fig. $1{ }^{1} \mathrm{H}$ NMR spectrum in $\mathrm{CDCl}_{3}$ of $\mathrm{CAR}-4$ apds. 
followed by temperature-sweeping rheological measurements (see Fig. S5 in the ESI $\dagger$ ). In its molten state, the monomer has a very low complex viscosity $\left(\eta^{*}\right)$ of $200 \mathrm{mPa}$, in the range needed for thermoset processes, such as infusion or resin transfer molding. After 15 minutes at $170{ }^{\circ} \mathrm{C}, \eta^{*}$ increases to 3 $\times 10^{4} \mathrm{mPa}$ s. Interestingly, a second rise is observed after 50 minutes, with $\eta^{*}$ reaching $4 \times 10^{6} \mathrm{mPa}$ s. After a detailed investigation, which can be found in the ESI (Fig. S6, S7, and $\mathrm{S} 8 \dagger$ ), it was concluded that the thermal curing of CAR-4apds follows a two-step process, combining both the benzoxazine ring cross-linking and the cardanol side-chain unsaturation homo-reaction. ${ }^{41}$ It is noteworthy that the catalytic opening of the lateral benzoxazine rings by thiols (COLBERT) could also happen. ${ }^{42-44}$ However, the absence of both thiols in the monomer, as revealed by Raman analysis (see Fig. S4 in the ESI $\dagger$ ), and benzoxazine/thiol adducts in the polymer, according to the NMR analysis of the soluble part (see Fig. S9 in the ESI $\dagger$ ), would indicate that such a reaction does not take place in the case of the polymerization of CAR-4apds.

CAR-4apds was degassed under vacuum and poured into a Teflon mold to be cured at $170{ }^{\circ} \mathrm{C}$ for $1 \mathrm{~h}$ and post-cured at $190{ }^{\circ} \mathrm{C}$ for 30 minutes, to form poly(CAR-4apds) (Scheme 1c). The polymer was analyzed by FTIR and DSC to confirm the completion of the reaction, as evidenced by the disappearance of the peaks at 1236 and $960 \mathrm{~cm}^{-1}$ (C-O-C asymmetric stretching and benzoxazine related modes, respectively) and the absence of any residual exothermic peak in DSC (see Fig. S7 and S10 in the ESI $\dagger)$. The glass transition temperature $\left(T_{\mathrm{g}}\right)$ of the material was $40{ }^{\circ} \mathrm{C}$, determined by the maximum loss factor by DMA (Fig. 2b). A low cross-link density value of $208.4 \mathrm{~mol} \mathrm{~m}^{-3}$ was calculated from the rubbery plateau modulus (see the ESI $\dagger$ for calculation details), as expected for a cardanol-made thermoset due to the dilution effect arising from its C15 alkyl side chain. Additionally, TGA of the polymer was performed which showed that the thermostability of poly (CAR-4apds) was not altered by the crosslinking process (Fig. S11 in the ESI $\dagger$ ). Finally, a summary of the thermal and mechanical properties of CAR-4apds and poly(CAR-4apds) is presented in Table 1.

Table 1 Thermal and mechanical properties of the CAR-4apds monomer (above) and poly(CAR-4apds) (below)

\begin{tabular}{lllll}
\hline CAR-4apds & & & & \\
$T_{\mathrm{m}}{ }^{a}\left({ }^{\circ} \mathrm{C}\right)$ & $T_{\mathrm{p}, \mathrm{o}}{ }^{b}\left({ }^{\circ} \mathrm{C}\right)$ & $T_{\mathrm{p}, \max }{ }^{c}\left({ }^{\circ} \mathrm{C}\right)$ & $\eta^{d}(\mathrm{mPa} \mathrm{s})$ & $t_{\mathrm{gel}}{ }^{e}(\mathrm{~min})$ \\
83 & 130 & 195 & 200 & 50 \\
Poly(CAR-4apds) & & & \\
$T_{\mathrm{g}}{ }^{f}\left({ }^{\circ} \mathrm{C}\right)$ & $T_{5 \%}{ }^{g}\left({ }^{\circ} \mathrm{C}\right)$ & $Y^{h}(\%)$ & $G^{\prime}(\mathrm{MPa})$ & $\nu^{j}\left(\mathrm{~mol} \mathrm{~m}^{-3}\right)$ \\
40 & 252 & 15 & 79.7 & 208.4
\end{tabular}

${ }^{a}$ Temperature of the endotherm peak by DSC. ${ }^{b}$ Onset temperature of the exotherm by DSC. ${ }^{c}$ Temperature of the exotherm peak by DSC. ${ }^{d}$ Viscosity at $50{ }^{\circ} \mathrm{C}$ by rheological measurements. ${ }^{e}$ Gelation time at $170{ }^{\circ} \mathrm{C}$ by rheological measurements. ${ }^{f}$ Glass transition temperature by DMA, maximum loss factor $\tan (\delta) .{ }^{g}$ Temperature of $5 \%$ of weight loss by TGA (Fig. S6 in the ESI $\dagger$ ). ${ }^{h}$ Char yield at $800{ }^{\circ} \mathrm{C}$ by TGA (Fig. S6 in the ESI $\dagger$ ). ${ }^{i}$ Storage moduli at $20{ }^{\circ} \mathrm{C}$ by DMA. ${ }^{j}$ Crosslinking density from DMA.

\section{Swelling properties}

Vitrimers may be considered a third class of polymers, combining the advantages from two other classes, i.e. thermoplastics and thermosets. Thermoplastics should flow when heated and be soluble in a suitable solvent. Thermosets are insoluble in solvents and cannot flow. Vitrimers will flow when heated and will also resist solvent dissolution. ${ }^{28}$ However, it is noteworthy that they may be partially soluble or damaged especially when exposed to a large amount of the solvent for long times. The swelling ability of poly(CAR-4apds) in dimethylformamide (DMF), ethylacetate (EtAc), ethanol, and acetone was investigated to confirm the formation of a $3 \mathrm{D}$ network and to assess the resistance to chemical solvents, which can be seen in the images of the samples displayed in the ESI (Fig. S12 $\dagger$ ). The solubility fractions and swelling ratios were determined after immersion of the samples for $48 \mathrm{~h}$ at $25{ }^{\circ} \mathrm{C}$ and they are reported in Table 2 . The uptake of acetone and ethanol was found to be $18 \%$ and $9 \%$, respectively. The solvent uptake in DMF, a good solvent for the monomer, was found to be $79 \%$ with a $23 \%$ soluble fraction, in the range of previously reported vitrimers. ${ }^{45}$ Furthermore, the physical integrity of the network was kept intact in spite of this significant swelling. A yellowing of the solvent solution was observed a couple of hours after the immersion of the samples, essentially composed of non-attached monomers of ring-opened CAR-4apds $\left({ }^{1} \mathrm{H}\right.$ NMR of the solution is available in the ESI in Fig. S9†). After changing the immersion solvent, coloration was no longer observed and the sample remained undissolved. The soluble fraction is explained by the low cross-linking density of the system.

The same experiment was carried out in neutral water (see Fig. S13 in the ESI $\dagger$ ). After $48 \mathrm{~h}$ of immersion in water at room temperature, it was not possible to detect any change in the weight of poly(CAR-4apds). The same results were obtained even after $48 \mathrm{~h}$ at $50{ }^{\circ} \mathrm{C}$. Water uptake is a major concern in the adhesive industry, as it contributes to the weakening of the structural adhesives commonly used. ${ }^{46}$ In consequence, the near-zero water uptake of poly(CAR-4apds) is a major asset.

\section{Stress relaxation}

One of the major characteristics of vitrimers is their gradual viscosity profile, showing a temperature dependence aligned with the chemical exchange reaction, following the Arrhenius law. Stress relaxation experiments were performed by rheological tests applying 1\% strain following the relaxation modulus as a function of time. Fig. 3a shows the stress relaxation curves

Table 2 Swelling ratio and soluble fraction of poly(CAR-4apds) after $48 \mathrm{~h}$ at $25^{\circ} \mathrm{C}$

\begin{tabular}{lll}
\hline Solvent & Swelling ratio & Soluble fraction \\
\hline DMF & 79 & 23 \\
EtAc & 72 & 19 \\
Acetone & 18 & 14 \\
Ethanol & 9 & $\sim 0$ \\
Neutral water & $\sim 0$ & $\sim 0$
\end{tabular}


a)

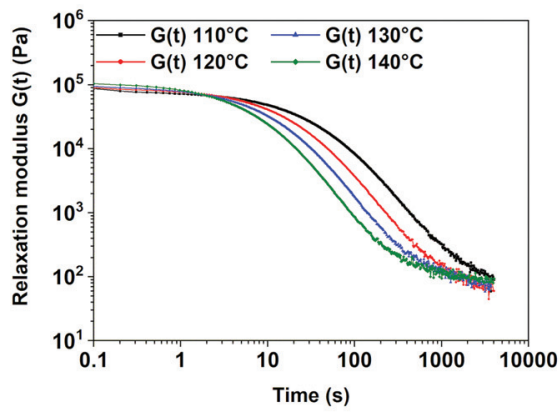

b)

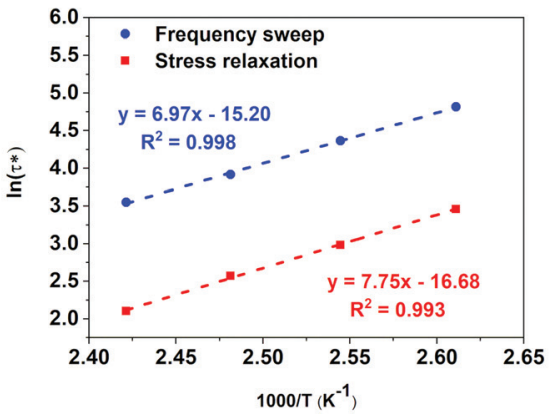

c)

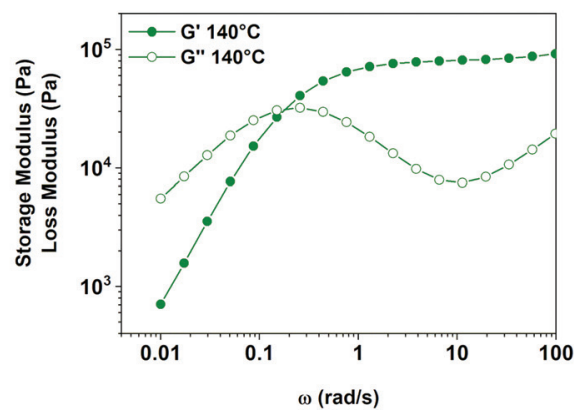

Fig. 3 (a) Stress relaxation curves for poly(CAR-4apds) between $110^{\circ} \mathrm{C}$ and $140^{\circ} \mathrm{C}$. (b) Arrhenius plots obtained from stress relaxation values where $G / G_{0}=1 / e$ and from $G^{\prime}$ and $G^{\prime \prime}$ crossover from frequency sweep tests, with fitting curves. (c) Frequency sweep curves for poly(CAR-4apds) at $140{ }^{\circ} \mathrm{C}$.

at different temperatures (from 110 to $140{ }^{\circ} \mathrm{C}$ ) exhibiting a complete and fast stress relaxation of poly(CAR-4apds). The relaxation times $\left(\tau^{*}\right)$ were found to follow the Maxwell law $G(t) /$ $G_{0}=\exp \left(-t / \tau^{*}\right)$, taken when the normalized stress decreased to a value of $0.37(1 / e) .^{47}$ Details of the calculation are reported in the ESI $\dagger$ as well as with the normalized stress relaxation curve (Fig. S14 in the ESI†). The relaxation time at $120{ }^{\circ} \mathrm{C}$ was 18 seconds. When $\tau^{*}$ at different temperatures was examined in an Arrhenius plot, a linear relationship was found, which is characteristic of vitrimer materials (Fig. 3b). ${ }^{26}$ From the slope of the linear trend line $\left(y=7.75 x-16.68 ; R^{2}=0.993\right)$, a mechanical activation energy of $64.5 \mathrm{~kJ} \mathrm{~mol}^{-1}$ was calculated (see the ESI $\dagger$ for calculation details). This value is in agreement with other systems reported in the literature. ${ }^{33}$ Additional frequency sweep measurements were performed at different temperatures. At $140{ }^{\circ} \mathrm{C}$ (Fig. 3c), the crossover of $G^{\prime}$ and $G^{\prime \prime}$ occurred around $0.19 \mathrm{rad} \mathrm{s}^{-1}$, which corresponds to a time of $33 \mathrm{~s}$. By monitoring the storage and loss moduli of these materials over different temperatures in the range of $110{ }^{\circ} \mathrm{C}$ to $140{ }^{\circ} \mathrm{C}$, we observed that the crossover shifted to lower frequency while maintaining the storage modulus constant at higher frequencies, confirming the associative nature of the chemical exchange. The full range frequency sweep tests are reported in the ESI (Fig. S15†).

In addition to the common glass transition temperature of polymers, the topology freezing transition temperature $\left(T_{\mathrm{v}}\right)$ is also a key characteristic of vitrimers. This concept was introduced in 2011 by Leibler $e t$ al. and corresponds to the temperature above which the network can be rearranged by dynamic exchange. ${ }^{26}$ This temperature is conventionally chosen at the point where the transition from solid to liquid occurs with a viscosity of $10^{12}$ Pa s. For the present system, a theoretical $T_{\mathrm{v}}$ was calculated from the extrapolation of the Arrhenius plot leading to a $T_{\mathrm{v}}$ of $-8.5^{\circ} \mathrm{C}$ (see the ESI $\dagger$ for calculation details). In this case, an intrinsically fast exchange reaction is embedded in a polymer network with a $T_{\mathrm{g}}$ higher than the $T_{\mathrm{V}}$, as already reported. ${ }^{27}$ This network is not frozen by the kinetics of the exchange reactions but by the lack of polymer chain mobility governed by the $T_{\mathrm{g}}$. At temperatures higher than the $T_{\mathrm{g}}$, the mobility of the network starts to allow rearrangements of the dynamic bonds, making the material both (re)processa- ble and reshapable. The relaxation properties of poly (CAR-4apds) were compared to those of a similar molecular system that did not contain disulfide bonds (poly(CAR-edan), Fig. S16†). Their comparison highlights the importance of the -S-S- bond in promoting dynamicity in the systems, as poly (CAR-edan) barely shows any relaxation after 1 hour at $100{ }^{\circ} \mathrm{C}$ (Fig. S16 in the ESI $\dagger$ ).

\section{Reprocessing, reshaping, and recycling}

Poly(CAR-4apds) was confirmed to be a vitrimer with fast stress relaxation, and we decided to investigate its reshaping and reprocessing ability at $120{ }^{\circ} \mathrm{C}$. First, a rectangular sample of poly(CAR-4apds) was reshaped by applying local heating and twisting it into a fusilli shape (Fig. 4). Once the sample cooled down to room temperature, the fusilli shape remained. The gradual variation of viscosity allows objects with complex shapes to be produced and/or existing parts to be reshaped without losing integrity. This is in contrast to what happens with thermoplastics where the viscosity drops dramatically with the temperature. Additionally, the cross-linked rectangular bar was ground into a powder with around $500 \mu \mathrm{m}$ diameter grains, and then placed inside a mold for a reshaping step at $120{ }^{\circ} \mathrm{C}$ for $1 \mathrm{~min}$ at a pressure of 5 bars. Fig. 4 shows the powder obtained from the ground material reshaped into a disc, confirming the possibility of re-processing and recycling the polybenzoxazine-based vitrimer.

Furthermore, similar thermo-mechanical properties were observed in the several-times-recycled material (from 1 to 5 recycling) and the pristine sample was assessed by rheological

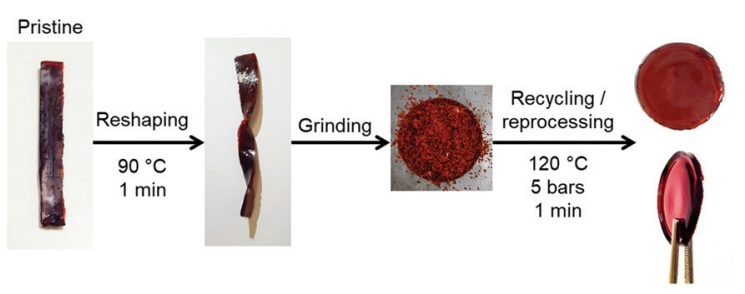

Fig. 4 Reshaping, (re)processing and recycling of the disulfide-benzoxazine vitrimer, poly(CAR-4apds). 


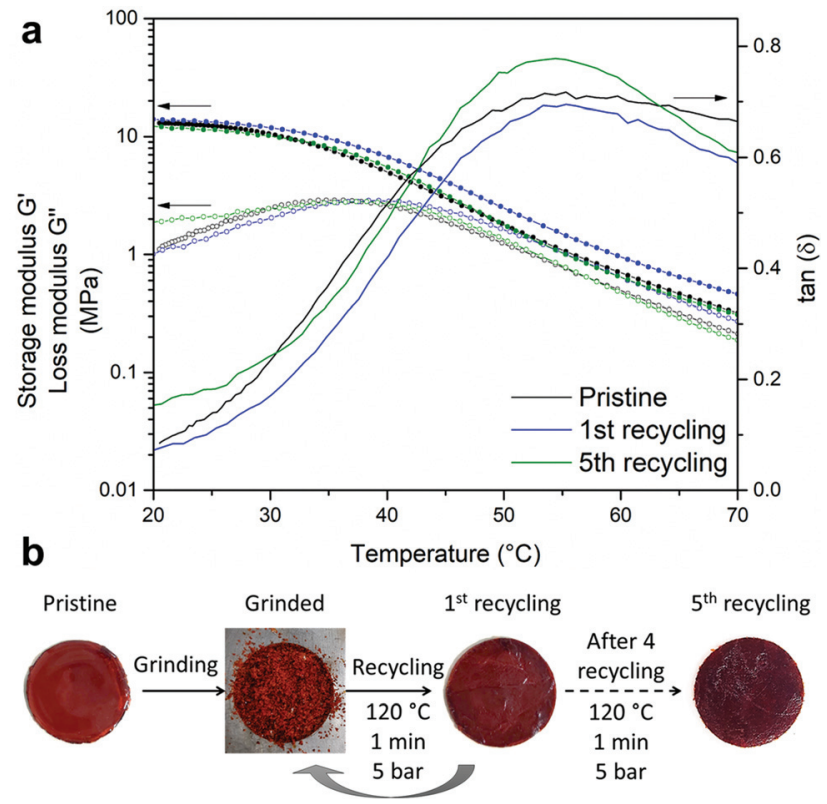

Fig. 5 (a) Dynamic mechanical thermal analyses of the pristine poly (CAR-4apds) and after the first and fifth reprocessing. (b) Reprocessing procedure to obtain discs.

tests as shown in Fig. 5a. The discs were prepared following the procedure described in Fig. $5 \mathrm{~b}$.

\section{Application as a self-healable adhesive}

The adhesive properties of poly(CAR-4apds) were assessed, inspired from previous reports on reversible adhesive vitrimers. ${ }^{48,49}$ Interestingly, poly(CAR-4apds) is malleable enough to be used as an adhesive. Contrary to conventional fluid-type adhesives (glue, cement, paste, etc.), poly (CAR-4apds) is solid at ambient temperature and easy to prepare as a film of controlled size and thickness. Thanks to its solid state, it is much more convenient to position than any other type of fluid-like adhesive, avoiding flooding outside of the surface to be glued. As shown in Fig. 6a, a $5 \times$ $5 \mathrm{~cm}^{2}$ poly(CAR-4apds) membrane was directly positioned and sandwiched between two aluminum cubes (see Fig. S17a and S17b in the ESI $\dagger$ ). After heat treatment at $120{ }^{\circ} \mathrm{C}$ at a pressure of 1 bar for 10 minutes, the whole adhesion process was complete. After cooling down the system to room temperature, a tensile test was performed to measure the adhesive strength, leading to the breakage of the assembly (see Fig. S18 in the ESI $\dagger$ ).

An adhesive fracture was observed (see Fig. S17c in the ESI $\dagger$ ). A schematic representation of the experiment is shown in Fig. 6a. After the tensile test, the two blocks were reassembled together by heating them at $120{ }^{\circ} \mathrm{C}$ for 10 minutes at a pressure of 1 bar. After the breaking, the process was repeated one more time. The initial adhesion force was found to be $1 \mathrm{kN}$ without showing a significant decrease after three breaking and two repairing steps (Fig. 6b). After the third breaking, the assembly was repaired with a new thermal treat-
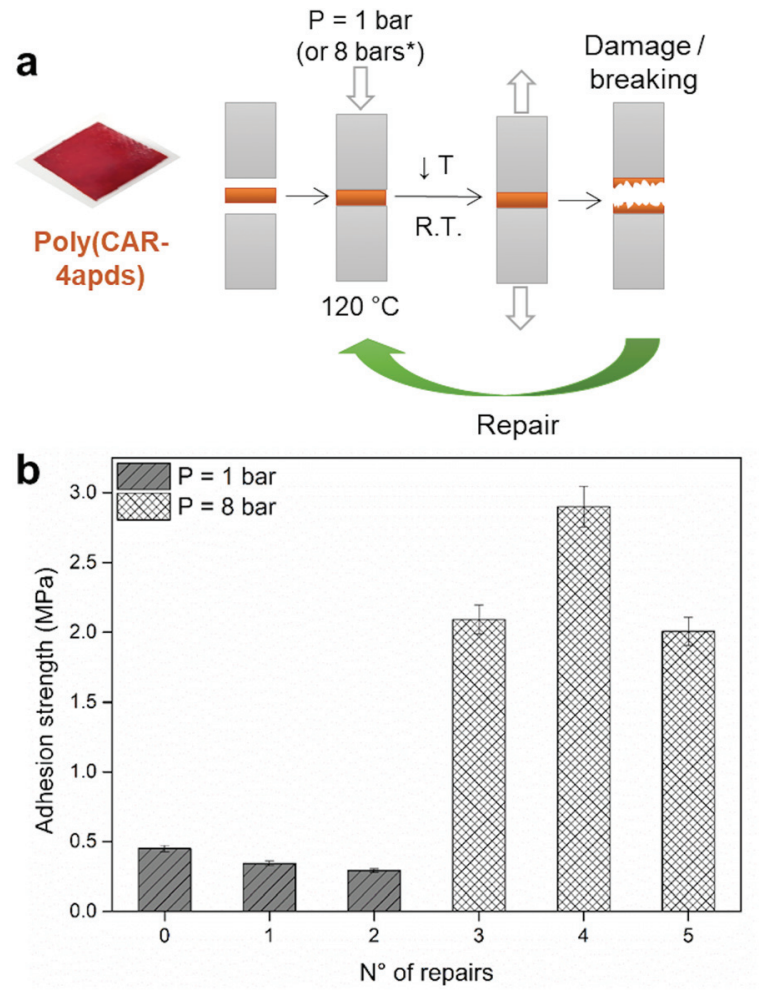

Fig. 6 Reversible and self-healing adhesive with the poly(CAR-4apds) membrane. (a) Illustration of the fabrication film from poly(CAR-4apds) and schematic representation of the adhesion test procedure. (b) Adhesive strength of the pristine sample and after 5 repair cycles.

ment at $120{ }^{\circ} \mathrm{C}$ for $10 \mathrm{~min}$, but this time applying a higher pressure of 8 bars. This led to an increase of the adhesive force to $5 \mathrm{kN}(2 \mathrm{MPa})$. This is quite close to the performance of structural adhesives, ${ }^{50}$ in particular, considering that poly (CAR-4apds) is not an optimal formulation. This process was repeated twice, even reaching an adhesive strength of $7 \mathrm{kN}(2.8$ MPa) (Fig. 6b). This may be due to interactions promoted at the vitrimer/aluminum interface due to the repeated tests, with a thin layer of poly(CAR-4apds) presumably being more and more tightly attached to the metal surface, making the healing process more efficient. At the end of the test, the vitrimer was disassembled and removed from the aluminum cubes by heating it at $120{ }^{\circ} \mathrm{C}$ for 10 minutes. After cooling, it was possible to reuse the membrane to re-bond the metal cubes. It is noteworthy that during the recycling process, a thiol-ene reaction could take place between the remaining double bonds of cardanol and sulfur radicals, as reported in the past. ${ }^{44,51,52}$ Under these conditions, sulfur radicals would be irreversibly consumed, thus decreasing the content of the dynamic exchangeable disulfide bonds. It would result in a decrease of the recyclability of poly(CAR-4apds). Even if FTIR measurements performed before and after the recycling steps did not reveal any molecular changes (Fig. S19 in the ESI†े), it does not mean such a reaction was not happening. However, to say the least, the material can be reused 5 times without showing any sign of deterioration. 
This experiment proves the possibility of using a disulfidebased benzoxazine vitrimer as a self-healing and reusable adhesive with a significant adhesive strength (up to 2.8 MPa under the conditions of experiments). The repairing process is performed at low temperatures, and short times are required making it feasible to use it in the industry without drastically increasing the cost.

\section{Conclusions}

Polybenzoxazines have been known for several years to be suitable alternatives to phenolic and epoxy resins. However they suffer from a similar drawback to traditional resins: once cured, their shape is permanent and they cannot be reused. Their after-life is limited to landfill burial or burning. This work reports the development of the first polybenzoxazine vitrimer, which can be reprocessed, reshaped, or recycled, based on dynamic disulfide exchanges. The synthesis of the monomer was carried in a solvent-less approach without the need for purification, limiting the generation of wastes even at the synthetic step. Additionally, the material was prepared from a cheap and renewable reagent, cardanol, fitting many of the green chemistry and engineering principles improving the sustainability of the full process from synthesis to final use. After polymerization by simple heating, the resulting polybenzoxazine can be reused thanks to a fast relaxation process $\left(18\right.$ seconds at $\left.120^{\circ} \mathrm{C}\right)$ which requires a low activation energy $\left(64.5 \mathrm{~kJ} \mathrm{~mol}^{-1}\right)$. Furthermore, the benzoxazine vitrimer shows adhesive properties ( $c a$. up to 2.8 MPa on aluminum) with short self-healing times at low temperatures making its use in industry and for the general public feasible. Moreover, the adhesion is reversible, a particularly useful asset for reducing material waste and time consumption in equipment, composite and material applications. Finally, this material could be considered in additive manufacturing, with the possibility of applying 3D printing technology for the design of materials of complex geometry, further extending its application to many fields of materials.

\section{Author contributions}

Acerina Trejo-Machin: Validation, investigation, writing - original draft, writing - review and editing. Laura Puchot: Validation, investigation, writing - original draft, writing review and editing. Pierre Verge: Conceptualization, validation, investigation, resources, writing - original draft, writing review and editing, supervision, project administration.

\section{Funding sources}

There are no funding sources to declare.

\section{Conflicts of interest}

There are no conflicts of interest to declare.

\section{Acknowledgements}

The authors are very thankful to Régis Vaudemont, Benoit Marcolini and Sebastien Gergen for the thermo-mechanical characterization and Denis Pittois for the elemental analyses.

\section{References}

1 Y. Zhu, C. Romain and C. K. Williams, Nature, 2016, 540, 354-362.

2 T. Keijer, V. Bakker and J. C. Slootweg, Nat. Chem., 2019, 11, 190-195.

3 H. Dodiuk and S. H. Goodman, in Handbook of Thermoset Plastics, ed. H. Dodiuk and S. H. Goodman, William Andrew Publishing, Boston, 3rd edn, 2014, pp. 1-12, DOI: 10.1016/B978-1-4557-3107-7.00001-4.

4 D. Ratna, Handbook of Thermoset Resins, iSmithers, 2009.

5 E. C. Agency, Annex XV Restriction report - Formaldehyde and formaldehyde releasers, ECHA, 2019.

6 H. Ishida, in Handbook of Benzoxazine Resins, ed. H. Ishida and T. Agag, Elsevier, Amsterdam, 2011, pp. 3-81, DOI: 10.1016/B978-0-444-53790-4.00046-1.

7 Y. Yagci, B. Kiskan and N. N. Ghosh, J. Polym. Sci., Part A: Polym. Chem., 2009, 47, 5565-5576.

8 K. Zhang, J. Liu, S. Ohashi, X. Liu, Z. Han and H. Ishida, J. Polym. Sci., Part A: Polym. Chem., 2015, 53, 1330-1338.

9 H. Ishida and D. J. Allen, J. Polym. Sci., Part B: Polym. Phys., 1996, 34, 1019-1030.

10 M. Kanchanasopa, N. Yanumet, K. Hemvichian and H. Ishida, Polym. Polym. Compos., 2001, 9, 367-375.

11 N. N. Ghosh, B. Kiskan and Y. Yagci, Prog. Polym. Sci., 2007, 32, 1344-1391.

$12 \mathrm{H}$. Manuspiya and H. Ishida, in Handbook of Benzoxazine Resins, ed. H. Ishida and T. Agag, Elsevier, Amsterdam, 2011, pp. 621-639, DOI: 10.1016/B978-0-444-53790-4.00081-3.

13 F. Shan, S. Ohashi, A. Erlichman and H. Ishida, Polymer, 2018, 157, 38-49.

14 G. Lligadas, A. Tüzün, J. C. Ronda, M. Galià and V. Cádiz, Polym. Chem., 2014, 5, 6636-6644.

15 Y. Lyu and H. Ishida, Prog. Polym. Sci., 2019, 99, 101168.

16 M. Monisha, N. Amarnath, S. Mukherjee and B. Lochab, Macromol. Chem. Phys., 2019, 220, 1800470.

17 L. Puchot, P. Verge, T. Fouquet, C. Vancaeyzeele, F. Vidal and Y. Habibi, Green Chem., 2016, 18, 3346-3353.

18 S. Shukla, N. Yadav and B. Lochab, in Advanced and Emerging Polybenzoxazine Science and Technology, ed. H. Ishida and P. Froimowicz, Elsevier, Amsterdam, 2017, pp. 451-472, DOI: 10.1016/B978-0-12-804170-3.00024-X.

19 O. Bayram, B. Kiskan, E. Demir, R. Demir-Cakan and Y. Yagci, ACS Sustainable Chem. Eng., 2020, 8, 9145-9155.

20 N. K. Sini, J. Bijwe and I. K. Varma, J. Polym. Sci., Part A: Polym. Chem., 2014, 52, 7-11.

21 R. Kirubakaran, P. Sharma, A. Manisekaran, J. Bijwe and L. Nebhani, J. Therm. Anal. Calorim., 2020, DOI: 10.1007/ s10973-019-09228-y. 
22 A. Trejo-Machin, P. Verge, L. Puchot and R. Quintana, Green Chem., 2017, 19, 5065-5073.

23 C. N. Bowman and C. J. Kloxin, Angew. Chem., Int. Ed., 2012, 51, 4272-4274.

24 W. Zou, J. Dong, Y. Luo, Q. Zhao and T. Xie, Adv. Mater., 2017, 29, 1606100.

25 C. J. Kloxin and C. N. Bowman, Chem. Soc. Rev., 2013, 42, 7161-7173.

26 D. Montarnal, M. Capelot, F. Tournilhac and L. Leibler, Science, 2011, 334, 965-968.

27 W. Denissen, J. Winne and F. Du Prez, Chem. Sci., 2016, 7, 30-38.

28 J. Winne, L. Leibler and F. Du Prez, Polym. Chem., 2019, 10, 6091-6108.

29 B. R. Elling and W. R. Dichtel, ACS Cent. Sci., 2020, 6(9), 1488-1496.

30 A. Rekondo, R. Martin, A. Ruiz de Luzuriaga, G. Cabañero, H. J. Grande and I. Odriozola, Mater. Horiz., 2014, 1, 237240.

31 D. J. Fortman, R. L. Snyder, D. T. Sheppard and W. R. Dichtel, ACS Macro Lett., 2018, 7, 1226-1231.

32 X. Li, R. Yu, Y. He, Y. Zhang, X. Yang, X. Zhao and W. Huang, ACS Macro Lett., 2019, 8, 1511-1516.

33 A. Ruiz de Luzuriaga, R. Martin, N. Markaide, A. Rekondo, G. Cabañero, J. Rodríguez and I. Odriozola, Mater. Horiz., 2016, 3, 241-247.

34 O. S. Taskin, B. Kiskan and Y. Yagci, Macromolecules, 2013, 46, 8773-8778.

35 B. Kiskan and Y. Yagci, J. Polym. Sci., Part A: Polym. Chem., 2014, 52, 2911-2918.

36 M. Arslan, B. Kiskan and Y. Yagci, Macromolecules, 2015, 48, 1329-1334.

37 M. Arslan, A. Motallebzadeh, B. Kiskan, A. L. Demirel, I. V. Kumbaraci and Y. Yagci, Polym. Chem., 2018, 9, 20312039.
38 M. Arslan, B. Kiskan and Y. Yagci, Macromolecules, 2018, 51, 10095-10103.

39 M. Arslan, B. Kiskan and Y. Yagci, Sci. Rep., 2017, 7, 5207.

40 P. Verge, L. Puchot, C. Vancaeyzeele, F. Vidal and Y. Habibi, in Advanced and Emerging Polybenzoxazine Science and Technology, ed. H. Ishida and P. Froimowicz, Elsevier, Amsterdam, 2017, pp. 89-107, DOI: 10.1016/B978-0-12804170-3.00007-X.

41 F. H. A. Rodrigues, J. R. R. Souza, F. C. F. França, N. M. P. S. Ricardo and J. P. A. Feitosa, e-Polym., 2006, 6, 081.

42 C. R. Arza, P. Froimowicz and H. Ishida, RSC Adv., 2016, 6, 35144-35151.

43 T. Urbaniak, M. Soto, M. Liebeke and K. Koschek, J. Org. Chem., 2017, 82, 4050-4055.

44 Z. Beyazkilic, M. U. Kahveci, B. Aydogan, B. Kiskan and Y. Yagci, J. Polym. Sci., Part A: Polym. Chem., 2012, 50, 40294036.

45 S. Dhers, G. Vantomme and L. Avérous, Green Chem., 2019, 21, 1596-1601.

46 P. Zinck and J.-F. Gérard, Polym. Degrad. Stab., 2008, 93, 1231-1237.

47 W. Denissen, M. Droesbeke, R. Nicolaÿ, L. Leibler, J. M. Winne and F. E. Du Prez, Nat. Commun., 2017, 8, 14857.

48 J. Tang, L. Wan, Y. Zhou, H. Pan and F. Huang, J. Mater. Chem. A, 2017, 5, 21169-21177.

49 S. Zhang, T. Liu, C. Hao, L. Wang, J. Han, H. Liu and J. Zhang, Green Chem., 2018, 20, 2995-3000.

50 A. Rudawska and M. Czarnota, J. Adhes. Sci. Technol., 2013, 27, 1933-1950.

51 J. Narayanan, M. J. Jungman and D. L. Patton, React. Funct. Polym., 2012, 72, 799-806.

52 H. Wang and Q. Zhou, ACS Sustainable Chem. Eng., 2018, 6, 12088-12095. 